\title{
Hyviä käytännön ratkaisuja hevostalleille
}

\author{
Elsa Roponen ${ }^{1)}$, Jaana Auer ${ }^{2)}$, Hanna Kaihlajärvi ${ }^{2)}$ \\ 1) Jyväskylän ammattikorkeakoulu, Biotalousinstituutti, Tuumalantie 17, 43130 Tarvaala, \\ elsa.roponen@outlook.com \\ 2) Jyväskylän ammattikorkeakoulu, Biotalousinstituutti, Tuumalantie 17, 43130 Tarvaala, \\ etunimi.sukunimi@jamk.fi
}

\section{TIIVISTELMÄ}

Hevostalous on suhteellisen kehittymätön kotieläintuotannon osa-alue Suomessa. Vain murto-osalla Suomen 16000 tallista on käytössään erilaisia teknisiä ratkaisuja, kuten lantaimureita ja heinä- tai väkirehuautomaatteja, työmäärän vähentämiseksi ja helpottamiseksi. Jyväskylän ammattikorkeakoulun Hevosvoimaa -tiedotushankkeen osana haastateltiin neljä eri tallinpitäjää tallitöitä helpottavista ratkaisuista.

Ruokinnan automatisointi tuo säästöä ajankäyttöön ja samalla työmäärän vähetessä se alentaa kustannuksia. Heinäautomaatti takaa rauhan talliin hevosten saadessa heinät samaan aikaan. Väkirehuautomaatilla annoskoot saadaan pienemmiksi ja näin ollen helpotetaan ruokinnan järjestelyä. Sekä heinäautomaatti että väkirehuautomaatti voivat toimia ajastimella. Ruokintaan saadaan helpotusta myös heinäverkkojen ja -häkkien avulla. Hevosten ahmiminen estyy, mikä on hyväksi ruuansulatuskanavalle. Lisäksi säästöä syntyy heinän kulutuksessa ja hevosten syöntiaika saadaan pidemmäksi, mikä vastaa luonnonmukaista syömiskäyttäytymistä.

Lannanpoiston helpottamiseen voi hyödyntää lantaimuria, joka vähentää huomattavasti työn kuormittavuutta sekä nopeuttaa karsinoiden siivousta. Lantaimurin voi asentaa myös jokaisen karsinan nurkkaan olevaan kaappiin, jonne saa imun päälle ja johon lanta heitetään. Korjattaessa vanhoja navetoita talleiksi on järkevää hyödyntää mahdolliset lantaraapat. Lantakourujen jäädessä karsinoiden alle peitetään kourut osaksi niin, että jokaiseen karsinaan jää luukku siivousta varten. Lantakouru voi kulkea myös keskellä käytävää karsinarivien välissä. Päivittäisen karsinan siivouksen pois jättämiseksi vaihtoehtona on olkipatja, jolloin karsinat tyhjennetään koneellisesti karsinan koosta/syvyydestä riippuen jopa vain 6 kk välein. Olkea tulee olla riittävästi ja sitä lisätään tarpeen mukaan viikoittain. Olki antaa hevosille tekemistä ja olkipatja tuo lämpöä talliin. Talliilma pysyy hyvänä oikeanlaisen ilmastoinnin avulla.

Myös pienet investoinnit, kuten imulakaisukoneen käyttö tallin käytävien ja pesupaikkojen siistinä pitämiseen nopeuttaa ja helpottaa työtä, kun lakaiseminen jää pois. Hyvät, oikeanlaiset työvälineet tuovat tehoa ja ergonomiaa tallityöskentelyyn. Automatisoinnissa on muistettava hevosten hyvinvointi ja niiden säännöllinen tarkkailu.

Tallia perustaessa vaihtoehtona voi olla myös aktiivitalli, jossa hevoset elävät laumaelämää ja pääsevät sisälle makuuhalliin aina niin halutessaan. Heinät voidaan jakaa joko automaateista tai ne voivat olla vapaasti saatavilla verkotettuina syönnin hidastamiseksi. Aktiivitallissa väkirehut jakaa automaatti, joka tunnistaa hevosen kaulapannasta ja antaa tarkan väkirehumäärän pantojen tietojen perusteella. Kokonaisrehumäärä voidaan jakaa 1-20 kertaa päivässä ja automaatti tunnistaa, jos hevonen on juuri käynyt ruokailemassa eikä anna uutta annosta heti perään. 15 hevosen aktiivitallissa päivittäisiin töihin kuluu aikaa korkeintaan 2 tuntia.

\section{Asiasanat}

Hevostallit, lantaimuri, heinäautomaatti, väkirehuautomaatti, imulakaisukone, aktiivitalli, työmenetelmät, automaatio, hevosenhoito 


\section{Johdanto}

Hevosharrastajien sekä hevostalouden ammatinharjoittajien määrä kasvaa Suomessa edelleen. Hevoset työllistävät koko- tai osa-aikaisesti 15 000-16 000 henkilöä. Vaikka hevosten ja tallien määrä kasvaa jatkuvasti, ei hevostallien tekninen kehitys ole mennyt eteenpäin niin kuin esimerkiksi karjataloudessa. Hevostalous on selvästi kehittymättömin kotieläintuotannon osa-alue Suomessa ja siksi hevospuolen harrastajat ja ammattilaiset tarvitsevat tietoa ja esimerkkejä tallitöitä helpottavista ja toimivista ratkaisuista. Tarkastelukohteina ovat toimivat ruokintaratkaisut, toimivat lannanpoistomenetelmät, toimivat tallitilat sekä aktiivitalli.

\section{Aineisto ja menetelmät}

Tiedonhankinta on tehty vierailemalla eri talleilla, joilla oli käytössään tallityötä helpottavia ratkaisuja. Pääkohteina oli neljä tallia, jotka valikoituivat vierailukohteeksi lehtiartikkelien, internetin ja erilaisia tallityötä helpottavia laitteita valmistavilta yrityksiltä saadun tiedon perusteella. Materiaali koostuu tallivierailuista, valokuvauksista sekä tallinomistajien haastatteluista. Tietoperustaan käytettiin lisäksi hevosalan kirjallisuutta sekä laitteiden valmistajilta saatua tietoa.

\section{Tulokset ja tulosten tarkastelu}

Väkirehuautomaatit (Kuvio 1. ja 2.) helpottavat ruokinnan järjestelyä. Ajastimella toimivat automaatit tiputtavat rehut hevosten eteen täsmälleen samaan aikaan. Automaattien täytöt tehdään kerran päivässä ja niihin mahtuu kahden ruokintakerran rehut. Väkirehuautomaattien lisäksi heinäautomaatit (Kuvio 3.) ovat hyvä ratkaisu helpottamaan tallityötä. Heinäautomaatitkin toimivat ajastimella ja niihin mahtuu kahden ruokintakerran heinät. Kun rehut tippuvat kaikille hevosille samaan aikaan, pysyy tallissa rauhallinen tunnelma. Vaikka työtä helpottavia ratkaisuja löytyy, täytyy kuitenkin muistaa, ettei hevosten tarkkailu saa kärsiä.

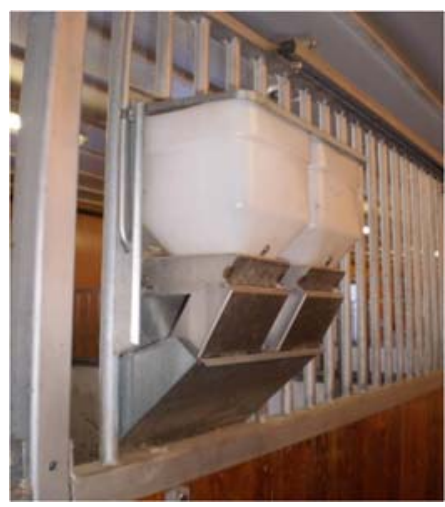

Kuvio 1. Ruokinta-automaatti käytävältä katsottuna

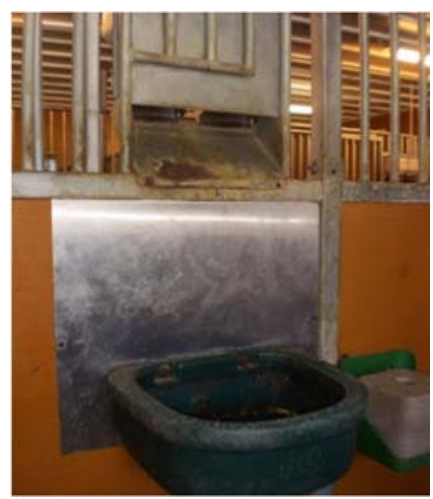

Kuvio 2. Ruokinta-automaatti karsinasta katsottuna

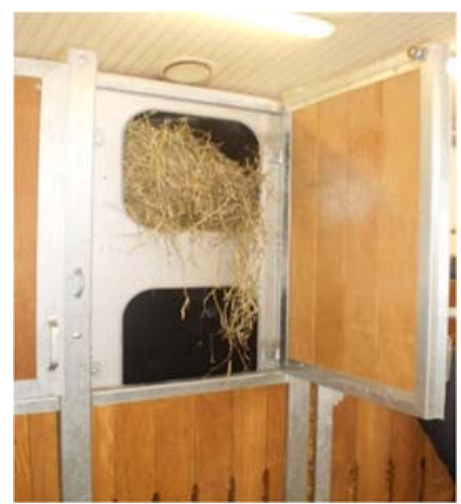

Kuvio 3. Heinä-automaatti

Heinäverkot (Kuvio 4.) ja -häkit auttavat, että hevoset eivät pääse ahmimaan heinää, vaan ruokailu tapahtuu hitaammin ja on näin ollen parempi myös ruuansulatukselle. Heinäverkot ja -häkit säästävät myös rehumäärissä. Hevoset eivät pääse tallomaan ja sotkemaan heiniä karsinaan tai tarhaan, joten rehunmenekki on huomattavasti pienempi. Aina ei tarvitse olla hienoin ja uusin versio esimerkiksi hidassyönti heinähäkistä, vaan sen pystyy toteuttamaan myös itse rakentamalla (Kuvio 5.). Myös tarhoissa ja pihatoissa on hyvä käyttää heinätelineitä (Kuvio 6.). Hevoset eivät pääse juurikaan vetämään heiniä silloin maahan. 


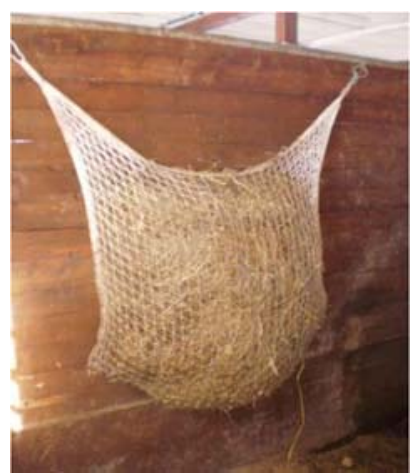

Kuvio 4. Heinäverkko

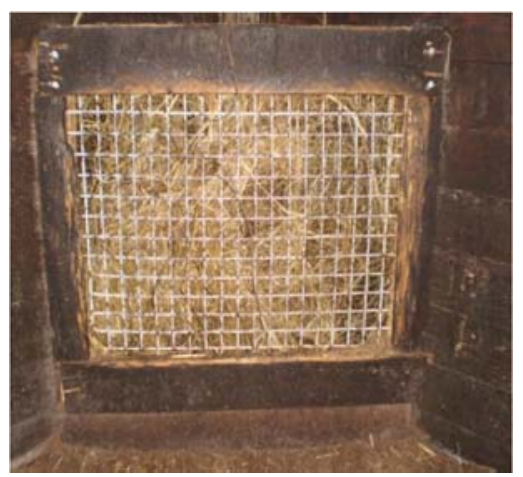

Kuvio 5. Hidassyöntihäkki

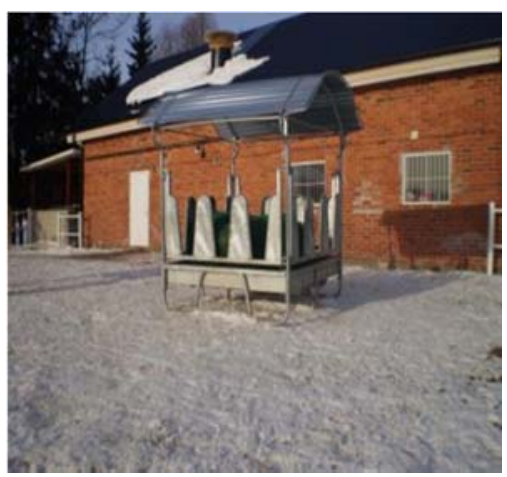

Kuvio 6. Heinäteline

Ruokintasukkulan avulla saadaan toteutettua tarkka ja yksilöllinen ruokinta. Sukkulaan voidaan täyttää annostus 1-4 eri rehulle. Ruokintasukkulaan kuuluu ohjaustietokone, josta näkee mm. tarkat tiedot ruokinnasta eli kuinka paljon mitäkin rehua kukin hevonen on saanut. Ruokintasukkulaan on mahdollista valita kaksi toiminnaltaan erilaista ohjaustietokonetta.

Hevosilla tulee olla aina puhdasta vettä saatavilla. Vesiautomaatit ovat jo tuttu näky talleilla ja niiden valmistajia ja malleja on hyvin monenlaisia. Vesiautomaatit helpottavat huomattavasti työtä, koska vettä ei tarvitse kantaa. Lämmitettävät vesiautomaatit takaavat veden saannin ulkotiloissa läpi talven.

Toimivista lannanpoistomenetelmistä lantaimuri (Kuvio 7.) nopeuttaa tallin siivoukseen kuluvaa aikaa ja on ergonomisempaa kuin perinteinen talikko ja kottikärry -menetelmä. Esimerkiksi 20 hevosen tallissa karsinoiden siivoukseen kuluu aikaa vain 1 tunti, kun käytössä on keskuspölynimurin lailla toimiva imuri. Talliilma on myös raikasta ja pölytöntä. Kuluvia osia ovat imurin imuputki, joka kuluu hankauksesta betonilattiaan. Muovinen putki ei ole suuri investointi uusia noin kerran vuodessa. Imuri toimii tehokkaasti ja on kevyt käyttää. Imuri on helppo rakennuttaa niin uusiin kuin vanhoihin talleihin ja kuivitus muotona ainakin turve, puru ja pelletti käyvät imuroimiseen hyvin. Imurilla pystytään myös imuroimaan tallin seinät, katot ja karsinat (Kuvio 8.). Lantaimureissa on myös vaihtoehtoja. Karsinan nurkassa voi olla luukku (Kuvio 9.), johon saa kaukosäätimellä imun päälle. Luukkuun heitetään talikolla lanta, joka kulkeutuu sieltä lantalaan.

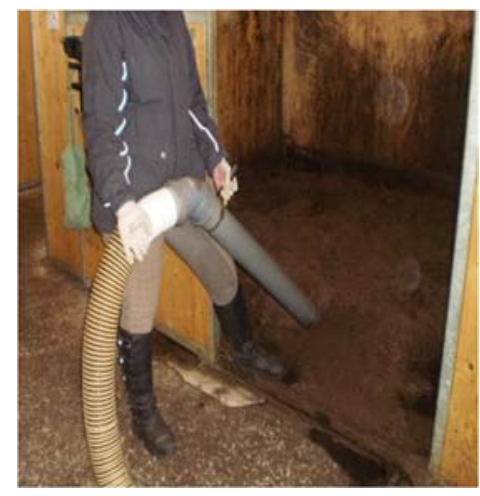

Kuvio 7. Lantaimuri

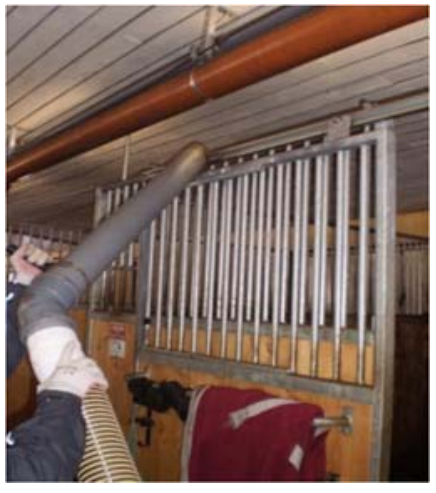

Kuvio 8. Lantaimurilla voi imuroida myös kattoa

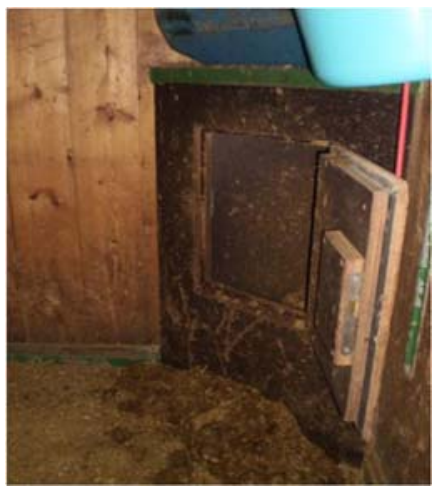

Kuvio 9. Karsinan nurkassa oleva lantaimurikaappi

Lannanpoistoa miettiessä voi huomioida myös mahdolliset vanhat lantakourut. Useat tallit ovat remontoitu vanhoihin navettoihin, joissa on saattanut olla lantakourut. Peruskorjauksessa lantakourut voi päällystää osaksi ja jättää karsinoiden kohdalle pieni avattava luukku, johon lanta heitetään. Lantakouruissa voi olla lantaraapat, jotka kuljettavat lannan lantalaan. Lantakourun päähän voidaan tarvittaessa sijoittaa mattokuljetin, joka siirtää lannan lantalaan. Kuljettimen avulla lantaa voidaan kasata korkeammalle.

Lantakärry voidaan sovittaa pienkuormaajaan sopivaksi. Lantakärry kulkee kevyesti tallin käytävällä, koska siinä on isot pyörät ja siihen mahtuu siivoamaan jopa 20 karsinaa. Täysi kärry otetaan pienkuormaajaan 
ja tyhjennetään lantalaan. Karsinoiden siivous on paljon sujuvampaa ja nopeampaa eikä raskaita kottikärryjä tarvitse työntää.

Lannan tyhjentäminen alaspäin on tärkeää, mikäli kottikärryjä vielä tarvitaan. Alaspäin tyhjennys on huomattavasti kevyempää työntekijälle. Lisäksi lantala tulisi sijoittaa niin, ettei sinne tarvitse kiertää ulkokautta. Näin vähennetään lämmön hukkaan pääsyä talvella, liukastumisia, venähdyksiä ja työaikaakin. Lantakärryjen kanssa kurassa tai lumessa ajaminen on erittäin työlästä.

Tallin lantalan lattian alle voi rakentaa vesikiertojärjestelmään pohjautuvan lämmitysjärjestelmän, joka ottaa lämpönsä lannasta. Tällä lannasta saadulla lattialämmityksellä voidaan lämmittää tallissa satulahuoneet, sosiaalitilat sekä hevosten pesupaikka. Lannasta saatu lämpö saadaan hyödynnettyä energiatehokkaasti.

Päivittäistä karsinan siivousta ei ole, jos hevosilla käytetään kuivikkeena olkipatjaa. Olkipatjan tyhjennys tapahtuu koneellisesti 8-10 viikon välein. Karsinoissa on hyvä olla sivuille kääntyvät väliseinät ja karsinarivien päissä tulee olla isot ovet, jotta tyhjennys traktorilla onnistuu helposti. Olkea lisätään karsinoihin pari kertaa viikossa. Olkipatjaa ei kovin usein näe talleilla, mikä on sen helppohoitoisuuden ja toimivuuden kannalta harmittavaa. Oljesta hevoset saavat tekemistä ja patja antaa myös lämpöä talliin. Olki myös vähentää hevosten vatsaongelmia ja häiriökäyttäytymistä.

Pienet investoinnit, kuten imulakaisukoneen (Kuvio 10.) käyttö tallin käytävien ja pesupaikkojen siistinä pitämiseen nopeuttaa ja helpottaa työtä, kun lakaiseminen jää pois. Kone ohjautuu herkästi, joten voimaa ei tarvita. Lisäksi käsikahvoissa on kaasu ja jarru, joten vauhtia voi säädellä helposti, eikä lattioiden lakaiseminen ole raskasta. Käytävien lakaiseminen perinteisesti harjalla on hidasta, nostattaa pölyä ja se on liikeradaltaan yksipuolista. Hyvät, oikeanlaiset työvälineet tuovat tehoa ja ergonomiaa tallityöskentelyyn.

Toimivissa hoito- ja pesutiloissa lattiamateriaali on miellyttävää eikä kopise. Kumimatto pesutilojen lattiassa estää liukastumisia ja hevoset seisovat siinä mielellään (Kuvio 11.). Pesutila tulee olla valoisa, koska hevonen menee mieluummin vaaleaan tilaan kuin pimeään ja ahtaaseen tilaan. Kun pesuletkut ovat turvallisesti telineissä tai kelalla (Kuvio 12.), ne eivät sotkeudu hevosten eikä hevostenhoitajien jalkoihin ja aiheuta vaaratilanteita. Pesutilojen riittävä koko on myös turvallisuustekijä.

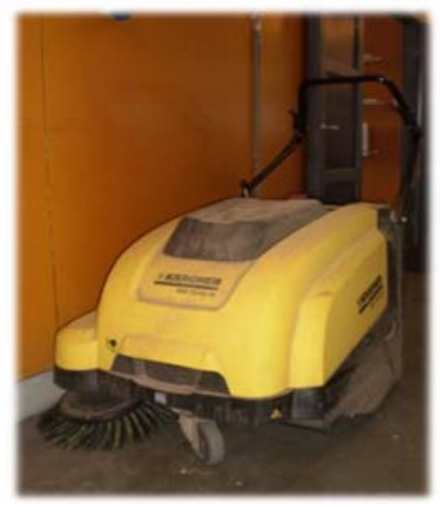

Kuvio 10. Imulakaisukone

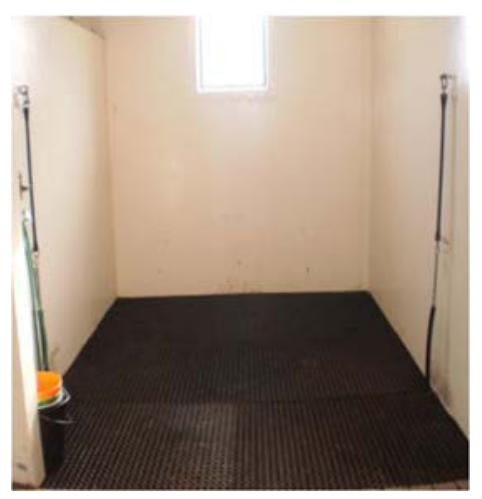

Kuvio 11. Kumimatto hevosten pesutilassa estää liukastumisia

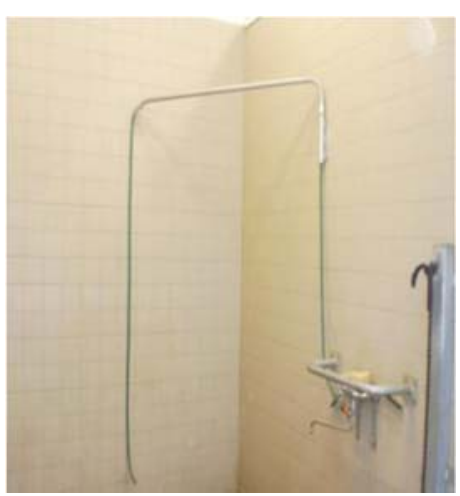

Kuvio 12. Hevosten pesutiloissa pesuletkujen tulee olla telineissä

Suomeen on perustettu muutamia aktiivitalleja. Ne tarjoavat hevosille ja poneille terveelliset ja luonnonmukaiset olot. Aktiivitallissa hevoset ja ponit elävät laumassa luonnonmukaista elämää. Hevoset pääsevät makuuhalliin tai ulos silloin kun haluavat ja hevoset syövät usein pieniä määriä kerrallaan ilman tarkkoja ruokinta-aikoja. Heinää on koko ajan tarjolla useamman kerran verkotetusta paalista, jotta syöminen tapahtuu mahdollisimman hitaasti. Väkirehuautomaatti (Kuvio 13.) tunnistaa hevoset kaulapannoissa (Kuvio 14.) olevan tiedon perusteella ja tiputtaa yksilöidyn rehuannoksen syömään tulijalle. Väkirehuautomaatille on portit niin etu- kuin takapuolella, jotta muut hevoset eivät pääse samaan aikaan ruokailemaan tai häiritse ruokailemassa olevaa hevosta tai ponia (Kuvio 15.). Automaatti myös tunnistaa, jos sama hevonen on juuri käynyt ruokailemassa eikä näin ollen anna heti perään uutta annosta. Rehumäärä jakaantuu hevosen päiväsaannin mukaan 1-20 kerralle ja se voi olla vain muutamia kymmeniä grammoja kerrallaan. Tämä on hevosen hyvinvoinnille tärkeä asia, sillä hevonen ei pysty sulattamaan suuria rehumääriä kerrallaan. 


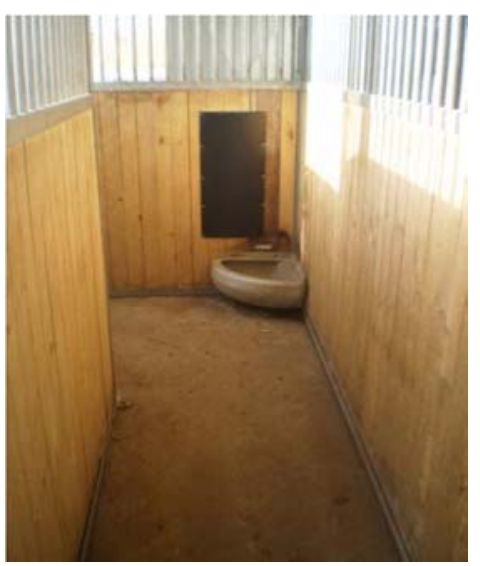

Kuvio 13. Ruokinta-automaatti

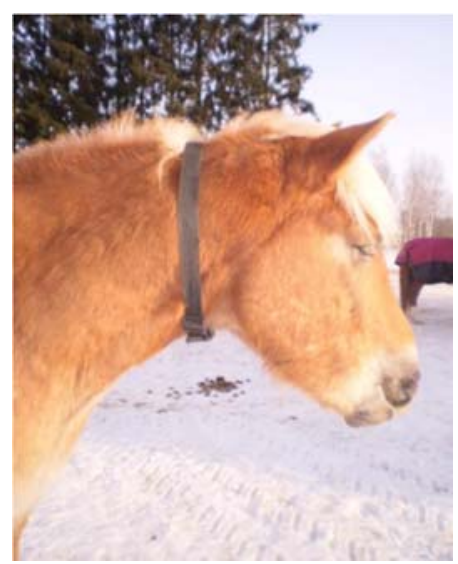

Kuvio 14. Hevosten tunnistus tapahtuu kaulapannan avulla

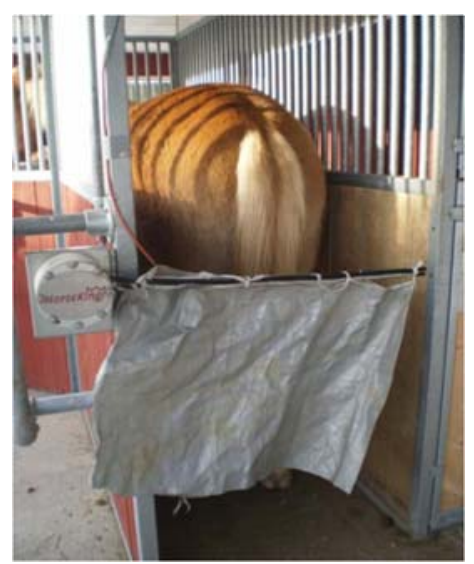

Kuvio 15. Väkirehuautomaatin takana on portti

\section{Johtopäätökset}

Työskentely tallilla vanhan ja totutun tavan mukaan on hyvin yleistä. Uusien tallityötä helpottavien ratkaisujen esittely innostaa hevosyrittäjiä ja hevostoimijoita ja antaa rohkeutta sekä innostusta kokeilla uusia menetelmiä tallitoiminnassa. Pienilläkin investoinneilla voidaan saada helpotettua tallitöitä, säästettyä työkustannuksia ja parannettua hevostalousyrittäjien ja tallihenkilökunnan jaksamista. Aina on kuitenkin huomioitava, että hevosten hyvinvointi on etusijalla eikä automatisointi ja tallitöiden helpotus saa vähentää hevosten tarkkailua ja niiden terveydentilan seurantaa.

\section{Kirjallisuus}

Roponen, E. 2013. Hyviä käytännön ratkaisuja hevostalleille. Opinnäytetyö. Jyväskylän ammattikorkeakoulu. Luonnonvara- ja ympäristöala. www.theseus.fi, http://urn.fi/URN:NBN:fi:amk-2013060613260 